\title{
How long does it take to coil an intracranial aneurysm?
}

\author{
Anjob N. de Gast • Aelwyn Soepboer • \\ Menno Sluzewski • Willem Jan van Rooij • \\ Guus N. Beute
}

Received: 8 June 2007 / Accepted: 8 August 2007 / Published online: 22 September 2007

(C) Springer-Verlag 2007

\begin{abstract}
Introduction The change in the treatment of choice for intracranial aneurysms from clipping to coiling has been associated with an important change in logistics. The time needed for coiling is variable and depends on many factors. In this study, we assessed the procedural time for the coiling of 642 aneurysms and tried to identify predictors of a long procedural time.

Methods The procedural time for coiling was defined as the number of minutes between the first diagnostic angiographic run and the last angiographic run after embolization. Thus, induction of general anesthesia and catheterization of the first vessel were not included in the procedural time. A long procedural time was defined as the upper quartile of procedural times (70-158 min). Logistic regression analysis was performed for several variables.

Results The mean procedural time was 57.3 min (median $52 \mathrm{~min}$, range $15-158 \mathrm{~min}$ ). More than half of the coiling procedures lasted between 30 and $60 \mathrm{~min}$. Multiple logistic regression analysis identified the use of a supportive device (OR 5.4), procedural morbidity (OR 4.5) and large aneurysm size (OR 3.0) as independent predictors of a long procedural time. A poor clinical condition of the patient, the rupture status of the aneurysm, gender, the
\end{abstract}

\footnotetext{
A. N. de Gast $\cdot$ A. Soepboer $\cdot$ M. Sluzewski $\cdot$ W. J. van Rooij $(\bowtie)$ Department of Radiology, St. Elisabeth Ziekenhuis,

Hilvarenbeekseweg 60,

5022 GC Tilburg, The Netherlands

e-mail: radiol@knmg.nl

G. N. Beute

Department of Neurosurgery, St. Elisabeth Ziekenhuis,

Tilburg, The Netherlands
}

occurrence of procedural rupture, and aneurysm location were not related to a long procedural time. The mean time for the first 321 coiling procedures was not statistically significantly different from mean time for the last 321 procedures.

Conclusion With optimal logistics, coiling of most intracranial aneurysms can be performed in one to two hours, including patient handling before and after the actual coiling procedure.

Keywords Intracranial aneurysms · Coiling ·

Procedural time

\section{Introduction}

Coiling of intracranial aneurysms has become the treatment of choice and has partly replaced neurosurgical clipping in most neurosurgical centers [1-3]. This change in treatment modality has been associated with an important change in logistics: patients are no longer treated in the operating room but in the radiology department. Coiling of intracranial aneurysms has to fit into the program of the angiography suite and an anesthetic team has to leave the operating room complex to assist in coiling. Since many aneurysms are treated acutely after subarachnoid hemorrhage (SAH), planning may be difficult. The time slot needed for coiling is variable and depends on many factors such as complexity of the aneurysm, the number of aneurysms that should be treated, the experience and skills of the treating endovascular team and local preferences. In this study, we assessed the procedural time for coiling of 642 aneurysms and tried to identify predictors of a long procedural time. 


\section{Patients and methods}

\section{Patients}

From January 1998 to September 2005, 817 aneurysms were coiled. The starting point of the study was chosen because of installation of a new biplane angiographic unit (Integris 3000 BN Neuro, Philips Medical Systems, Best, The Netherlands) at the end of 1997.

We excluded 65 patients (with 146 aneurysms) with more than one aneurysm coiled in the same session. Of the remaining 671 aneurysms, 642 had complete imaging data available for review. The time of each angiographic run was printed on the images automatically. The procedural time for coiling was defined as the number of minutes between the first diagnostic angiographic run and the last angiographic run after embolization. Thus, induction of general anesthesia and catheterization of the first vessel were not included in the procedural time. In the vast majority of patients, 3-D rotational angiography (3DRA) of the vessel harboring the aneurysm was performed [4]. Many patients with acute SAH confirmed on CT scan were immediately transferred to the angiography suite and underwent complete diagnostic angiography and coiling of the aneurysm under general anesthesia. Only in patients with unruptured aneurysms, was diagnostic angiography usually available before coiling, and in these patients only 3DRA was performed during the process of coiling.

Of the 642 patients, 178 were men and 464 were women with a mean age of 52.9 years (median 52 years, range 1983 years). Of the 642 aneurysms, 523 had ruptured and 119 had not. Among the 523 patients with a ruptured aneurysm at the time of treatment, clinical condition was Hunt and Hess (HH) I/II in 337, HH IV/V in 68, and HH III in 118. The mean aneurysm size was $8.0 \mathrm{~mm}$ (range 2-55 $\mathrm{mm}$ ). The aneurysm was located in the posterior circulation in 154 , in the anterior cerebral artery in 246, in the middle cerebral artery in 46, and in the carotid artery in 196 patients. The type of coil used was mostly Guglielmi detachable coils (GDC; Boston Scientific, Fremont, Calif.), followed by TruFill/Orbit coils (Cordis Neurovascular, Miami Lakes, Fl.) and straight coils $50 \mathrm{~cm}$ long (Cook Detach, Cook, Copenhagen, Denmark) for large and giant aneurysms [5]. A supportive device was used during coiling in 60 aneurysms, a supportive balloon in 55, a TriSpan in 4, and a stent in 1 aneurysm [6]. In 26 aneurysms a procedural rupture occurred. Complications leading to permanent neurological deficit or death occurred in 40 patients $[7,8]$.

\section{Statistical analysis}

To assess possible predictors of a long procedural time, we defined a long procedural time as the upper quartile of the procedural times $(70-158 \mathrm{~min})$ and performed logistic regression analysis for the following variables: male gender, age greater than the median age of 52 years, ruptured aneurysm, aneurysm size in the upper quartile (10-55 mm), occurrence of procedural rupture, HH grade III-V, occurrence of procedural morbidity defined as complications leading to death or permanent neurological deficit [7, 8], use of a supportive device, location on the anterior cerebral artery, carotid artery or middle cerebral artery, and location in the posterior circulation. Subsequently, to identify independent predictors, multiple logistic regression analysis was performed for all significant predictors.

To assess whether recent technical developments had influenced procedural time, we compared the mean procedural time of the first 321 aneurysms with the mean procedural time of the last 321 aneurysms using a $t$-test. In addition, we assessed whether the implementation of 3DRA in October 2000 had influenced procedural time.

\section{Results}

The mean procedural time was 57.3 min (median 52 min, range 15-158 $\mathrm{min})$. More than half of the coiling procedures lasted between 30 and 60 min (Fig. 1), 49 procedures (7.6\%) lasted less than $30 \mathrm{~min}$, and 68 procedures (10.6\%) lasted more than $90 \mathrm{~min}$.

Median and mean procedural times with ranges and standard deviations for aneurysm coiling procedures in relation to patient and aneurysm characteristics are summarized in Table 1. The predictors of a long procedural time are displayed in Table 2. The use of a supportive device was the strongest predictor of a long procedural time (OR 5.4), followed by the occurrence of procedural morbidity (OR 4.5), a large aneurysm size (OR 3.0), and patient age (OR 1.5). A poor clinical condition of the patient, rupture status of the aneurysm, gender, occurrence of procedural

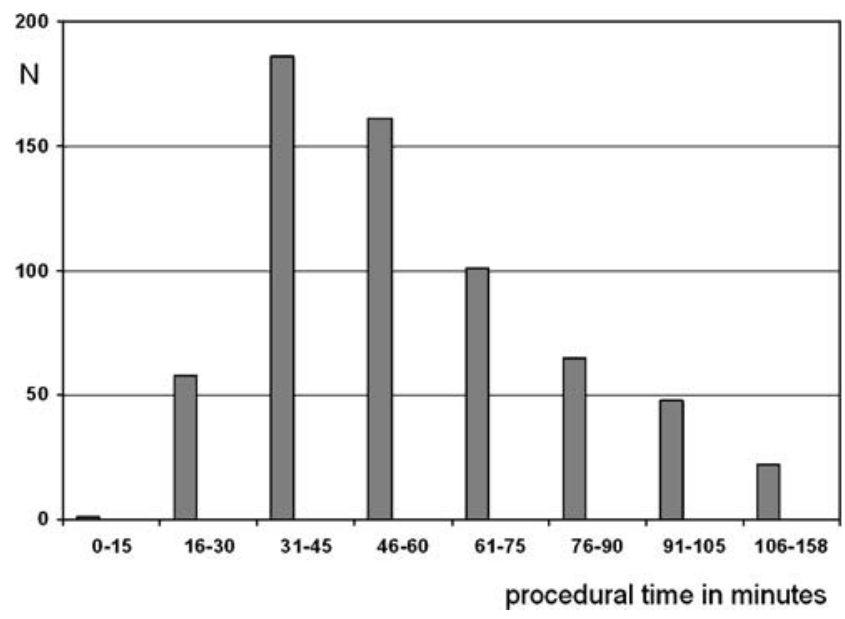

Fig. 1 Procedural times in minutes for 642 coiling procedures displayed as number of procedures in 15 -min time periods 
Table 1 Procedural times for all 642 aneurysms in relation to patient and aneurysm characteristics

\begin{tabular}{|c|c|c|c|c|c|}
\hline \multirow[t]{2}{*}{ Variable } & \multirow{2}{*}{$\begin{array}{l}\text { No. of } \\
\text { aneurysms }\end{array}$} & \multicolumn{4}{|c|}{ Procedural time (min) } \\
\hline & & Median & Mean & Range & $\begin{array}{l}\text { Standard } \\
\text { deviation }\end{array}$ \\
\hline $\begin{array}{l}\text { Aall } \\
\text { aneurysms }\end{array}$ & 642 & 57.3 & 52.0 & $15-158$ & 24.1 \\
\hline $\begin{array}{l}\text { Use of } \\
\text { supportive } \\
\text { device }\end{array}$ & 60 & 80.5 & 80.2 & $35-150$ & 30.7 \\
\hline $\begin{array}{r}\text { Procedural } \\
\text { morbidity }\end{array}$ & 40 & 72.5 & 75.6 & $28-158$ & 30.7 \\
\hline $\begin{array}{l}\text { Aneurysm } \\
\text { size in } \\
\text { upper quartile } \\
(10-55 \mathrm{~mm})\end{array}$ & 163 & 64 & 70.5 & $25-158$ & 26.4 \\
\hline $\begin{array}{l}\text { Age more } \\
\text { than median } \\
52 \text { years }\end{array}$ & 321 & 55 & 60.7 & $17-158$ & 25.0 \\
\hline $\begin{array}{l}\text { Hunt and Hess } \\
\text { grade III-V }\end{array}$ & 186 & 54 & 59.2 & $18-122$ & 22.6 \\
\hline $\begin{array}{l}\text { Ruptured } \\
\text { aneurysm }\end{array}$ & 523 & 52 & 58.1 & $16-158$ & 24.6 \\
\hline Male gender & 182 & 55 & 60.4 & $17-131$ & 23.8 \\
\hline $\begin{array}{l}\text { Procedural } \\
\text { rupture }\end{array}$ & 26 & 50 & 53.8 & $16-107$ & 21.3 \\
\hline \multicolumn{6}{|l|}{ Aneurysm location } \\
\hline $\begin{array}{l}\text { Middle cerebral } \\
\text { artery }\end{array}$ & 46 & 53 & 61.8 & $19-131$ & 26.8 \\
\hline $\begin{array}{l}\text { Posterior } \\
\text { circulation }\end{array}$ & 154 & 54 & 61.7 & $22-146$ & 27.1 \\
\hline $\begin{array}{l}\text { Anterior } \\
\text { cerebral artery }\end{array}$ & 246 & 53.5 & 57.1 & $16-112$ & 21.2 \\
\hline Carotid artery & 196 & 48 & 53.1 & $15-158$ & 23.9 \\
\hline \multicolumn{6}{|c|}{ Implementation of 3-D angiography } \\
\hline Before & 167 & 52 & 58.6 & $18-158$ & 25.5 \\
\hline After & 475 & 52 & 56.9 & $15-146$ & 23.7 \\
\hline
\end{tabular}

rupture, aneurysm location, and implementation of 3DRA had no influence on procedural time. Multiple logistic regression analysis identified the use of a supportive device, occurrence of procedural morbidity, and large aneurysm size as independent predictors of a long procedural time.

The mean procedural time for the first 321 coil procedures was $56.5 \mathrm{~min}$ (median $51 \mathrm{~min}$, range 18-158 $\mathrm{min}$ ) and for the last 321 this was $58.1 \mathrm{~min}$ (median $54 \mathrm{~min}$, range 15$124 \mathrm{~min})$. This difference was not significant ( $t$-test, $P=0.40)$

\section{Discussion}

In this study, the mean procedural time for coiling was $57 \mathrm{~min}$. Most procedures were performed within $1 \mathrm{~h}$.
Procedural time was defined as the time between the first and the last angiographic run, since this time period could easily be assessed from time prints on the images. The time for patient preparation, anesthetic care, insertion of angiographic sheet and catheterization of the first vessel were not included in the procedural time. In our department, this additional time is usually between 30 and $45 \mathrm{~min}$. This means that the typical time needed for coiling of an intracranial aneurysm is around one and a half hours, varying from one to two hours.

A long procedural time was associated with the use of a supportive device, occurrence of procedural morbidity and large aneurysm size. Although coiling of middle cerebral artery aneurysms tended to take more time and coiling of carotid artery aneurysms tended to take less time, these differences were just not statistically significant. The strongest predictor of a long procedural time was the use of a supportive device, mostly a supportive balloon [6]. When the use of a supportive device is not anticipated from the beginning of the procedure, an additional guiding catheter must be placed in the groin and navigated to the vessel harboring the aneurysm, or the guiding catheter has to be changed for a catheter with larger inner lumen. In addition, the balloon catheter has to be prepared and navigated across the neck of the aneurysm and this may be time consuming since 0.010 -inch guidewires are usually difficult to steer. Another predictor of a long procedural time was large aneurysm size. In larger aneurysms a higher number of coils can usually be inserted and the accumulated electrolytic detachment time thus increases. The last predictor of a long procedural time was the occurrence of morbidity (not the occurrence of procedural rupture). Most morbidity is caused by thromboembolic complications. Several actions may be undertaken when such a complication occurs, such as mechanical thrombus fragmentation and

Table 2 Odds ratios with $95 \%$ confidence intervals for different variables for the upper quartile of procedural times $(70-158 \mathrm{~min})$

\begin{tabular}{lll}
\hline Variable & Odds ratio & $95 \% \mathrm{CI}$ \\
\hline Use of supportive device & 5.40 & $3.11-9.34$ \\
Procedural morbidity & 4.49 & $2.33-8.64$ \\
Aneurysm size in upper quartile $(10-55 \mathrm{~mm})$ & 3.03 & $2.06-4.45$ \\
Age more than median age & 1.47 & $1.02-2.10$ \\
Hunt and Hess grade III-V & 1.32 & $0.88-1.97$ \\
Ruptured aneurysm & 1.41 & $0.87-2.30$ \\
Male gender & 0.79 & $0.54-1.16$ \\
Procedural rupture & 0.73 & $0.27-1.98$ \\
Aneurysm location & & \\
Middle cerebral artery & 1.81 & $0.97-3.40$ \\
Posterior circulation & 1.30 & $0.87-1.95$ \\
Anterior cerebral artery & 0.93 & $0.65-1.35$ \\
Carotid artery & 0.68 & $0.46-1.02$ \\
Implementation of 3D angiography & 1.11 & $0.74-1.66$ \\
\hline
\end{tabular}


selective injection of thrombolytic drugs, which both lead to a longer procedural time.

It is of note that no difference in procedural time was found between the earlier and later procedures, despite the technical advances in microcatheters and guidewires and increased experience. In both groups, there was no difference in mean aneurysm size $(8.7$ versus $7.2 \mathrm{~mm})$, use of a supportive device (both 30) or occurrence of morbidity (both 20). We did not include the first 3 years of coiling in our hospital because the time was not printed on the images by the angiographic equipment used during that period. The mean procedural time may have been longer on the steep side of the learning curve during those first 3 years.

In our high-volume department, logistics have been optimized. In patients scheduled for coiling, an intravenous line and urinary catheter are placed on the ward, the treating endovascular team is experienced, a biplane angiographic unit with 3DRA is available, all catheters and devices needed are available in the angiography room, microcatheters and guidewires are prepared by technicians, and in recent years the puncture site is closed with a dedicated device. For coiling of large and giant aneurysms, we use for the most part mechanically detachable coils $50 \mathrm{~cm}$ long. All anesthetists involved in coil procedures were experienced, with no residents in training. Our time slot for anesthesia is in the afternoon from 1300 to 1600 hours with a "deadline" at 16.30 , after which time an anesthetist on call has to be notified to take over care. With these logistics we normally plan two patients, and regularly treat three patients within this time slot.

Both of the senior authors (M.S. and W.J.v.R) have performed many coil procedures in four other hospitals in The Netherlands. The procedural time may differ greatly between centers, depending on many factors such as availability of single- or biplane angiographic equipment and 3DRA, the experience of the operator, supporting technicians and anesthetic team, and local preferences such as liberal or restricted use of supportive devices.

\section{Conclusion}

With optimal logistics, coiling of most intracranial aneurysms can be performed in one to two hours, including patient handling before and after the actual coiling procedure.

Conflict of interest statement We declare that we have no conflict of interest.

\section{References}

1. Molyneux A, Kerr R, Stratton I, Sandercock P, Clarke M, Shrimpton J, Holman R (2002) International Subarachnoid Aneurysm Trial (ISAT) of neurosurgical clipping versus endovascular coiling in 2143 patients with ruptured intracranial aneurysms: a randomised trial. Lancet 360:1267-1274

2. Mejdoubi M, Gigaud M, Tremoulet M, Albucher JF, Cognard C (2006) Initial primary endovascular treatment in the management of ruptured intracranial aneurysms: a prospective consecutive series. Neuroradiology 48:899-905

3. Slob MJ, Sluzewski M, van Rooij WJ (2005) The relation between packing and reopening in coiled intracranial aneurysms: a prospective study. Neuroradiology 47:942-945

4. Hirai T, Korogi Y, Suginohara K, Ono K, Nishi T, Uemura S, Yamura M, Yamashita Y (2003) Clinical usefulness of unsubtracted 3D digital angiography compared with rotational digital angiography in the pretreatment evaluation of intracranial aneurysms. AJNR Am J Neuroradiol 24:1067-1074

5. Sluzewski M, Menovsky T, van Rooij WJ, Wijnalda D (2003) Coiling of very large or giant cerebral aneurysms: long-term clinical and serial angiographic results. AJNR Am J Neuroradiol 24:257-262

6. Sluzewski M, van Rooij WJ, Beute GN, Nijssen PC (2006) Balloon-assisted coil embolization of intracranial aneurysms: incidence, complications, and angiography results. J Neurosurg 105:396-399

7. van Rooij WJ, Sluzewski M, Beute GN, Nijssen PC (2006) Procedural complications of coiling of ruptured intracranial aneurysms: incidence and risk factors in a consecutive series of 681 patients. AJNR Am J Neuroradiol 27:1498-1501

8. van Rooij WJ, Sluzewski M (2006) Procedural morbidity and mortality of elective coil treatment of unruptured intracranial aneurysms. AJNR Am J Neuroradiol 27:1678-1680 